\author{
Loyalitas Kreativitas \\ Aldi Masyarakat Kreatif
}

P-ISSN 2722-2101, E-ISSN 2722-4201

Program Studi Ekonomi Manajemen Universitas Pamulang Jurnal LOKABMAS Kreatif Vol.02,No.01,Maret 2021 Hal. 29-35

Email:jurnalkreatif.manajemen@gmail.com

\title{
PENERAPAN INTERACTIVE MARKETING DALAM UPAYA MENINGKATKAN PENJUALAN UMKM BAGI WARGA KELURAHAN BABAKAN TANGERANG SELATAN DI MASA PANDEMI COVID-19
}

\author{
Yusran Daeng Matta, Muhammad Yuda Alhabsyi, Muhammad Mansyur, \\ Riski Dwi Nugroho, Heri Priyanto.
}

\begin{abstract}
Email dosen02331@unpam.ac.id, dosen02296@unpam.ac.id, emmansyur@yahoo.co.id . dosen00805@unpam.ac.id, dosen01824@unpam.ac.id
\end{abstract}

\begin{abstract}
ABSTRAK
Tujuan dari Kegiatan Pengabdian Kepada Masyarakat adalah untuk melaksanakan salah satu Tri Dharma Perguruan Tinggi. Selain itu diharapkan dengan pengabdian kepada masyarakat tersebut keberadaan perguruan tinggi dapat memberikan kontribusi besar kepada pengembangan dan penerapan keilmuan kepada masyarakat.

Metode kegiatan yang digunakan adalah pelatihan tanggal 20 s.d 21 Juli 2020. Seminar ini bertujuan agar masyarakat dapat meningkatkan kreatifitas dan inovasi dalam mendirikan atau menjalankan UMKM.

Hasil pengabdian masyarakat yang diperoleh adalah bertambahnya keilmuan bagi Para siswa dan siswi agar mereka memiliki pandangan yang baik tentang memnafaatkan media system informasi atau online dalam menjalankan bisnis UMKM pada masa covid-19 ini.

Ilmu yang diperoleh pada Pengabdian Masyarakat kali ini diharapkan mampu memberikan semangat baru bagi kita dalam menyampaikan materi dan motivasi serta berkontribusi bagi generasi muda, baik dilingkungan sekolah, kampus, masyarakat dan keluarga.
\end{abstract}

Keywords: Penerapan Interactive Marketing, UMKM

\begin{abstract}
The purpose of Community Service Activities is to carry out one of the Tri Dharma of Higher Education. In addition, it is hoped that with this community service, the existence of universities can make a major contribution to the development and application of science to the community.

The activity method used is training from 20 to 21 July 2020. This seminar aims to increase creativity and innovation in running or running MSMEs.

The results of community service obtained are obtaining knowledge for students and students so that they have a good view of utilizing information or online media systems in running MSME businesses during the Covid-19 period.

The knowledge obtained at this Community Service is expected to be able to provide new enthusiasm for us in conveying material and motivation as well as contributing to the younger generation, both in the school, campus, community and family environment.
\end{abstract}

Keywords: Application of Interactive Marketing, UMKM 


\section{PENDAHULUAN}

Interactive marketing merupakan suatu kegiatan yang bersifat online dan program untuk mempengaruhi konsumen secara langsung maupun tidak langsung serta untuk membangun citra atau menjual produk. Dunia digital diprediksi akan menjadi poin krusial bagi seluruh aktivitas manusia, termasuk aktivitas bisnis. Beberapa indikator yang bisa digunakan saat ini antara lain naiknya pengeluaran iklan digital, pertumbuhan kepemilikan smartphone yang menyediakan kemudahan akses internet, perbaikan infrastruktur telekomunikasi dalam rangka peningkatan kualitas akses data, serta diluncurkannya layanan 4G. Menurut data Facebook, 74\% pengguna internet di Indonesia menggunakan perangkat mobile (Utomo, 2016).

Pesatnya perkembangan teknologi, dunia digital dan internet tentu juga berimbas pada dunia pemasaran. Tren pemasaran di dunia beralih dari yang semula konvensional (offline) menjadi digital (online). Strategi digital marketing ini lebih prospektif karena memungkinkan para calon pelanggan potensial untuk memperoleh segala macam informasi mengenai produk dan bertransaksi melalui internet.

Platform yang sering digunakan dalam digital marketing adalah media sosial atau jejaring sosial. Jejaring sosial yang tersedia terkadang memiliki karakteristik yang berbeda. Ada yang sifatnya untuk pertemanan seperti Facebook, Path, Instagram, dan Twitter, ada pula yang khusus untuk mencari dan membangun relasi seperti yang ditawarkan Linkedin. Selain itu tersedia pula media yang lebih pribadi seperti electronic mail (e-mail) dan pesan teks. Search engine seperti Google dan Yahoo pun dapat diberdayakan.

Selain itu pelaku usaha juga dapat memanfaatkan media blog ataupun situs pribadi. Data yang dilansir oleh We are Social, sebuah agensi digital marketing di Amerika, menyebutkan bahwa platform media sosial yang paling banyak digunakan di Indonesia per Januari 2017 adalah Youtube (49\%) dan oleh Facebook $(48 \%)$. Posisi selanjutnya ditempati oleh Instagram (39\%), Twitter (38\%), Whatsapp $(38 \%)$, dan Google $(36 \%)$. Sisanya ditempati secara berurutan oleh FB Messenger, Line,
Linkedin, BBM, Pinterest, dan Wechat (Kemp, 2017).

Usaha Mikro, Kecil dan Menengah (UMKM) memiliki peran penting dalam laju ekonomi Indonesia terutama dalam penciptaan lapangan kerja dan pemberdayaan rumah tangga yang mendukung pendapatan rumah tangga. Keberadaan UMKM diharapkan mampu memacu perekonomian di tengah perlambatan ekonomi yang terjadi saat ini. Pemanfaatan konsep pemasaran berbasis teknologi digital (digital marketing) memberikan harapan bagi UMKM untuk berkembang menjadi pusat kekuatan ekonomi. Era digital memang tidak mungkin untuk dihindari. Pakar pemasaran Yuswohadi mengungkapkan bahwa jika ingin bertahan, maka pelaku UMKM harus mampu memaksimalkan manfaat perkembangan digital (Maulana, 2017).

Para pelaku UMKM tersebut terhadang kendala masih minimnya pengetahuan terhadap digital marketing dan electronic commerce (ecommerce). Potensi pemanfaatan digital marketing ini mengharuskan masyarakat untuk melek teknologi, oleh karena itu diperlukan sosialisasi dan pelatihan penggunaan teknologi informasi dan komunikasi ini. Kegiatan pengabdian masyarakat mengenai pemanfaatan digital marketing ini diharapkan dapat memberikan pengetahuan dan pemahaman serta dapat menginspirasi pelaku UMKM dalam memanfaatkan teknologi internet dan jejaring sosial sebagai alat untuk menjalankan bisnisnya.

Penulis dan tim tertarik untuk mengkaji sejauh mana pemanfaatan digital marketing yang telah dilakukan oleh pelaku Penerapan Interactive Marketing dalam Upaya Meningkatkan Penjualan UMKM Bagi Warga Kelurahan Babakan Tangerang Selatan di Masa Pandemi Covid-19.

\section{RUMUSAN MASALAH}

Berdasarkan uraian di atas, terdapat beberapa permasalahan sebagai berikut:

1. Terjadi peralihan tren pemasaran dari konvensional (offline) ke digital (online).

2. Jumlah pelaku usaha khususnya UMKM yang memanfaatkan digital marketing tidak 
dengan jumlah pertumbuhan $\begin{gathered}\text { sebanding } \\ \text { pengguna }\end{gathered}$ internet.

3. Masih sedikit pelaku UMKM yang tidak paham bagaimana cara melakukan digital marketing dengan memanfaatkan jejaring sosial.

\section{TUJUAN PELAKSANAAN}

Kegiatan pengabdian masyarakat ini bertujuan untuk:

1. Memberikan pengetahuan dan pemahaman kepada pelaku UMKM mengenai pentingnya digital marketing bagi usaha mereka;

2. Mengajarkan praktik digital marketing dengan memanfaatkan jejaring sosial kepada pelaku UMKM.

Kompetensi yang diharapkan tercapai dari kegiatan ini adalah:

1. Pengetahuan dan pemahaman pelaku UMKM yang menjadi peserta akan pentingnya digital marketing bagi usaha mereka;

2. Kemampuan pelaku UMKM yang menjadi peserta dalam mempraktikkan digital marketing dengan memanfaatkan jejaring sosial.

\section{TINJAUAN PUSTAKA}

Interactive Marketing (Digital Marketing/ pemasaran online) dapat didefinisikan sebagai kegiatan marketing termasuk branding yang menggunakan berbagai media berbasis web (Sanjaya \& Tarigan, 2009). E-Marketing atau digital marketing diartikan sebagai penggunaan teknologi digital untuk mencapai tujuan pemasaran serta upaya pengembangan atau penyesuaian konsep pemasaran itu sendiri, dapat berkomunikasi dalam cakupan global, dan mengubah cara perusahaan melakukan bisnis dengan pelanggan (Ali, 2013). Digital marketing merupakan pemasaran dengan menggunakan penerapan teknologi secara digital. Salah satu bentuk marketing digital dengan menggunakan media elektronik atau internet adalah internet marketing (emarketing). E-Marketing merupakan suatu proses pemasaran yang menggunakan teknologi komunikasi elektronik, khususnya internet. Peran strategi digital marketing dapat menjadi hal yang penting dalam mengikuti perkembangan teknologi digital dan mengembangkan rencana untuk menarik konsumen dan mengarahkannya pada perpaduan antara komunikasi elektornik dan komunikasi tradisional (Chaffey, Chadwick, Mayer, \& Johnston, 2009).

Menurut Chaffey (2009:10) retensi tersebut dapat dicapai dengan meningkatkan pengetahuan tentang konsumen seperti profil, perilaku, nilai, dan tingkat loyalitas, kemudian menyatukan komunikasi yang ditargetkan dan pelayanan online sesuai kebutuhan masingmasing individu. Digital marketing adalah kegiatan marketing termasuk branding yang menggunakan berbagai media berbasis web seperti blog, website, e-mail, adwords, ataupun jejaring sosial (Sanjaya \& Tarigan, 2009). Wardhana (2015) menemukan bahwa strategi digital marketing berpengaruh hingga $78 \%$ terhadap keunggulan bersaing UMKdalam memasarkan produknya. Pemanfaatan digital marketing memiliki beberapa keunggulan, antara lain:

1. Target bisa diatur sesuai demografi, domisili, gaya hidup, dan bahkan kebiasaan;

2. Hasil cepat terlihat sehingga pemasar dapat melakukan tindakan koreksi atau perubahan apabila dirasa ada yang tidak sesuai;

3. Biaya jauh lebih murah daripada pemasaran konvensional;

4. Jangkauan lebih luas karena tidak terbatas geografis;

5. Dapat diakses kapanpun tidak terbatas waktu

6. Hasil dapat diukur, misalnya jumlah pengunjung situs, jumlah konsumen yang melakukan pembelian online;

7. Kampanya bisa dipersonalisasi;

8. Bisa melakukan engagement atau meraih konsumen karena komunikasi terjadi secara langsung dan dua arah sehingga pelaku usaha membina relasi dan menumbuhkan kepercayaan konsumen.

Di sisi lain, digital marketing pun memiliki kelemahan, di antaranya: 
ditiru oleh pesaing;

\section{Mudah}

2. Dapat disalahgunakan oleh pihak-pihak tidak bertanggung jawab;

3. Reputasi menjadi tidak baik ketika ada respon negatif;

\section{METODE PELAKSANAAN}

Metode kegiatan yang digunakan adalah dengan melakukan kunjungan langsung ke kelurahan desa Babakan Tangerang Selatan pada tanggal 18 sd 20 November 2020.

Kegiatan pengabdian kepada masyarakat dilakukan dengan metode sebagai berikut :

1) Identifikasi masalah yang dilakukan sebagai langkah awal untuk merumuskan apa saja yang akan dijadikan bahan untuk perancangan system dan materi pelatihan dalam kegiatan pengabdian ini.

2) Melakukan survey lapangan ke Keluarahan Babakan Tangerang Selatan sebagai tempat dilaksanakannya kegiatan kemudian melakukan proses wawancara dan diskusi dengan pihak Kelurahan untuk identifikasi permasalahan yang ada dalam lingkungan Keluarahan Babakan Tangerang Selatan.

3) Kontribusi pengusul dalam proses pengabdian dengan melakukan penelitian pustaka untuk acuan materi yang digunakan selama kegiatan pengabdian.

Pelatihan ini bertujuan agar masyarakat atau warga pelaku UMKM keluarahan Babakan Tangerang Selatan dapat memanfaatkan teknologi menjadi suatu alat dalam menerapkan proses interactive marketing untuk meningkatkan penjualannya.

\section{HASIL DAN PEMBAHASAN}

Berdasarkan wawancara, tanya jawab dan pengamatan langsung selama kegiatan berlangsung, kegiatan pengabdian pada masyarakat ini memberikan hasil sebagai berikut :
1. Memberikan pengetahuan kepada masyarakat dan mahasiswa mengenai pemanfaatan interactive marketing untuk kemajuan UMKM.

2. Memberikan pengetahuan kepada masyarakat agar menciptakan UMKM yang krea

3. Memberikan gambaran dan pengetahuan kepada masyarakat Babakan Pamulang mengenai cara mendirikan dan mengembangkan UMKM di masa covid19.

Dan beberapa faktor yang mendukung terlaksananya kegiatan pengabdian pada masyarakat ini adalah besarnya minat dan antusiasme peserta selama kegiatan, sehingga kegiatan berlangsung dengan lancar dan efektif. Sedangkan faktor penghambatnya adalah keterbatasan waktu pelatihan dan fasilitas peralatan yang masih minim.

\section{KESIMPULAN DAN SARAN \\ Kesimpulan}

Dari kegiatan pengabdian pada masyarakat ini dapat disimpulkan bahwa:

1) Interactive marketing merupakan suatu kegiatan yang bersifat online dan program untuk mempengaruhi konsumen secara langsung maupun tidak langsung serta untuk membangun citra atau menjual produk.

2) Semakin meningkatnya ide dan kreatifitas maka UMKM akan semakin maju dan mendapatkan keuntungan yang besar.

\section{Saran}

Mengingat besarnya manfaat kegiatan pengabdian pada masyarakat ini, maka selanjutnya perlu:

1) Mengadakan sosialisasi dan pelatihan serupa pada masyarakat dengan jumlah peserta yang lebih banyak untuk menciptakan usaha kerja mandiri atau seperti UMKM.

2) Adanya kesinambungan program pasca kegiatan pengabdian ini sehingga msyarakat dapat memanfaatkan gadget dan modal yang ia miliki. 


\section{DAFTAR PUSTAKA}

Aditya wardhana. (2015). Strategi Digital Marketing dan Implikasinya Pada Keunggulan Bersaing UMKdi Indonesia. In Seminar Nasional Keuangan dan Bisnis IV (pp. 327337). Universitas Pendidikan Indonesia.

Ali, H. (2013). Marketing dan Kasus-Kasus Pilihan. Yogyakarta: CAPS.

Arikunto, S. (2010). Prosedur penelitian : Suatu Pendekatan Praktik. (Edisi Revisi). Jakarta: Rineka Cipta.

Canavan, O., Henchion, M., \& O'Reilly, S. (2007). The use of the internet as a marketing channel for Irish speciality food. International Journal of Retail and Distribution Management. https://doi.org/10.1108/09590550710728110

Chaffey, D., Chadwick, F. E., Mayer, R., \& Johnston, K. (2009). Internet Marketing: Strategy, Implementation, and Practice. United States: Prentice Hall.

Elburdah, R. P., Pasaribu, V. L. D., Rahayu, S., Septiani, F., \& Metarini, R. R. A. (2021). MOMPRENEUR PENOPANG PEREKONOMIAN KELUARGA DI MASA PANDEMI COVID-19 DENGAN BISNIS ONLINE PADA KELURAHAN PONDOK BENDA. Abdi Laksana: Jurnal Pengabdian Kepada Masyarakat, 2(1), 75-82.

Pasaribu, V. L. D., Agrasadya, A., Shabrina, N., \& Krisnaldy, K. (2020). Menjadi Enterpreneur Muda Yang Memiliki Jiwa Leadership Untuk Menghadapi Masa Depan. Abdi Laksana: Jurnal Pengabdian Kepada Masyarakat, 1(1). 


\author{
Loyalitas Kreativitas \\ Aldi Masyarakat Kreatif
}

P-ISSN 2722-2101, E-ISSN 2722-4201

Program Studi Ekonomi Manajemen Universitas

Pamulang

Jurnal LOKABMAS Kreatif Vol.02,No.01,Maret 2021

Hal. 29-35

Email:jurnalkreatif.manajemen@gmail.com 


\author{
Loyalitas Kreativitas \\ Aldi Masyarakat Kreatif
}

P-ISSN 2722-2101, E-ISSN 2722-4201

Program Studi Ekonomi Manajemen Universitas

Pamulang

Jurnal LOKABMAS Kreatif Vol.02,No.01,Maret 2021

Hal. 29-35

Email:jurnalkreatif.manajemen@gmail.com 